\title{
Adolescência e função paterna: Da gestação ao primeiro ano de vida do bebê
}

\author{
Camila Guedes Henn \\ Psicóloga \\ Cesar Augusto Piccinini \\ Universidade Federal do Rio Grande do Sul
}

\begin{abstract}
Resumo
O presente estudo teve por objetivo investigar o exercício da função paterna na adolescência, desde a gestação até o primeiro ano de vida do bebê. Participaram deste estudo três casais de adolescentes, cuja gestação estava no terceiro trimestre no momento do primeiro contato. Os participantes tinham idades entre 16 e 19 anos e, no momento da gestação, estavam namorando ou morando juntos, e eram de nível socioeconômico baixo. Cada caso foi investigado em três diferentes etapas: terceiro trimestre de gestação, após três meses e após um ano de vida do bebê. Os resultados revelaram que os pais foram identificados como importantes fontes de apoio emocional para suas jovens companheiras, tanto no período da gestação, quanto no puerpério, apesar de algumas dificuldades em relação ao exercício de outras funções terem sido identificadas.
\end{abstract}

Palavras-chave: paternidade; pais adolescentes; função paterna.

\begin{abstract}
Abtract
Adolescence and paternal function: From pregnancy to the first year of baby's life. The present study aimed to investigate the exercise of the paternal function in adolescence, from pregnancy through the first year of baby's life. The study included three teenage couples whose pregnancy was in the third trimester at the time of first contact. Participants were aged between 16 and 19 years and at the time of pregnancy, were dating or living together, and were of low socioeconomic status. Each case was investigated in three different stages: third trimester of pregnancy, after three months and after a year of baby's life. The results revealed that parents were identified as important sources of emotional support for their young partners, both during pregnancy and in the postpartum, despite some difficulties regarding the exercise of other functions have been identified.
\end{abstract}

Keywords: fatherhood; adolescent fathers; paternal function.

\section{Resumen}

Adolescencia y función paterna: Una mirada al primer año de vida del bebé. El presente estudio tuvo como objetivo investigar el ejercicio de la función paterna en la adolescencia, desde el embarazo hasta el primer año de vida del bebé. En el estudio participaron tres parejas de adolescentes cuyo embarazo estaba en el tercer trimestre cuando el primer contacto. Los participantes, durante el embarazo, tenían edades comprendidas entre los 16 y los 19 años, eran novios o vivian juntos, y eran de nivel socioeconómico bajo. Cada caso fue investigado en tres etapas diferentes: en el tercer trimestre del embarazo, después de tres meses y después de un año de vida del bebé. Los resultados revelaron que los padres fueron identificados como importantes fuentes de apoyo emocional para sus jóvenes compañeras, tanto durante el embarazo e en el puerperio, a pesar de algunas dificultades en relación con el ejercicio de otras funciones han sido identificados.

Palabras clave: paternidad; padres adolescentes; función paterna.

$\mathrm{O}$ pai tem uma função fundamental na vida da criança, desde os primeiros momentos de sua vida e mesmo na gestação. Para Stern (1997), o pai possui uma grande importância em relação à constituição da matriz de apoio, que faz parte da constelação da maternidade, cujas funções seriam: proteger fisicamente a mãe e prover suas necessidades vitais, de forma a permitir um afastamento necessário das exigências da realidade externa e possibilitar sua dedicação ao bebê, bem como valorizar e apoiar a mulher e fazer com que se sinta instruída e ajudada em seu papel de mãe. 
Ao tomar como base a perspectiva de Winnicott para a reflexão da função do pai dentro da psicanálise, considera-se justamente a possibilidade de analisar como se dá esta função num período que antecede o Complexo de Édipo, a partir dos primeiros meses de vida do bebê (Fulgêncio, 2007). Ao longo do seu trabalho, Winnicott (1965/1979) traz diversos apontamentos em relação à função do pai: como precioso para ajudar a mãe a sentir-se bem em seu corpo e feliz em seu espírito; como aquele que lhe dá apoio moral, sendo o sustentador da autoridade que ela implanta na vida da criança; e como aquele que enriquece a vida da criança, trazendo suas qualidades positivas e sua vivacidade. De acordo com Winnicott (1965/1979), uma das coisas mais importantes que um pai pode fazer ao filho é estar vivo e continuar vivo durantes seus primeiros anos. É justamente a partir deste aspecto que o autor parece introduzir a função da mãe: como intermediadora da relação pai-filho, e como quem facilita o conhecimento mútuo entre eles. Mais do que isso, parece destacar a importância de a mãe reconhecer a função do pai na vida dos filhos, não apenas nos momentos em que ele se faz presente fisicamente, mas também o confirmando através de sua fala. Por outro lado, Winnicott ressalta que a presença física deste pai real é importante na vida da criança, como forma de ela poder vê-lo como um ser ideal, mas, ao mesmo tempo, confrontar-se com o pai real, com imperfeições e também com a capacidade de acolher e sobreviver aos seus ataques.

$\mathrm{Na}$ verdade, os laços de filiação dependem do nível de investimentos que são feitos reciprocamente pelos familiares e, por conseguinte, do reconhecimento que cada um faz destes no interior da família (Passos, 2005). Sendo assim, ressalta a autora, faz-se fundamental que cada sujeito se reconheça em uma determinada posição dentro da família e, ao mesmo tempo, que consiga legitimar a posição do outro. De forma semelhante, Le Camus (2002) diz ser necessário que a mãe transmita ao filho que ele não é tudo para ela, mas que há também um pai e um marido. Do mesmo modo, de acordo com o autor, para ser mãe, é necessário que a mulher seja reconhecida e aceita pelo pai. Ou seja, para ele, ambos os cônjuges são mutuamente pais. A partir deste pressuposto, pode-se pensar que, para que pais e mães consigam exercer suas funções da forma esperada, faz-se necessário que, da mesma forma, legitimem-se uns aos outros nestas funções.

Ainda em relação à função do pai na vida da criança, Le Camus (2002) faz uma crítica justamente a pouca ênfase dada ao estudo da paternidade nos primeiros anos de vida da criança, ou melhor, no período pré-edípico. De acordo com o autor, impregnados pelas ideias de Lacan, os psicanalistas do período pós-guerra atribuíram pouca importância à contribuição paterna precoce, subestimando o efeito estruturante da ternura pré-edipiana do pai. Entretanto, Le Camus (2002) se remete às importantes concepções atuais de alguns clínicos e psicólogos do desenvolvimento a respeito dos pais para enunciar duas propostas que ele considera "inovadoras e realistas". A primeira é a de que a prática da autoridade do pai, entendida a partir da colocação de regras e limites na vida da criança, não é inteiramente incompatível com o aporte de segurança, compreensão e afeto. Para ele, a verdadeira autoridade de um pai é aquela que deriva da vontade de fazer crescer, e da confiança nas potencialidades da criança, a partir da escuta e do diálogo. Já a segunda diz respeito ao fato de que, para Le Camus (2002), o dever e o direito de proibir, bem como o uso de castigos justificados e medidos, não ficam restritos à "função paterna", mas são contribuições que os pais têm que assumir conjuntamente com as mães, numa atitude coparental.

Sem colocar em dúvida a importância dos cuidados maternais, os quais considera sempre "um passo à frente" dos paternos, pela maneira mais biológica e corporal do relacionamento da mãe com o filho, Le Camus (2002) ressalta, no entanto, que a contribuição do pai na construção da personalidade da criança não pode ser reduzida à função simbólica. De acordo com o autor, é cada vez mais admitido que a criança tenha muito a ganhar com a presença imediata, ativa e calorosa de seu pai. Nesse sentido, tendo como base um modelo de pai comprometido, mas psicologicamente diferenciado da mãe, ele aponta algumas possíveis contribuições que o pai traz à vida da criança, que são: a de agente de socialização, parceiro na comunicação, e tutor nas aprendizagens cognitivas.

De modo geral, os aspectos aqui mencionados referem-se à paternidade quando esta acontece como uma crise normativa, ou seja, esperada para a fase adulta do ciclo vital. Por outro lado, a ocorrência deste fenômeno não permanece circunscrita apenas à idade adulta, podendo acontecer durante a adolescência.

Até recentemente, o estudo da parentalidade na adolescência parecia ser um tema que privilegiava a visão das mães adolescentes, o que gerou uma lacuna em relação aos estudos sobre os pais adolescentes (Cabral, 2003; Dias \& Aquino, 2006; Schelemberg, Pereira, Grisard, \& Hallal, 2007; Tuffin, Rouch, \& Frewin, 2010). De acordo com Tuffin et al. (2010), esta pouca preocupação em incluir os pais nos estudos sobre parentalidade na adolescência pode ter se dado em decorrência da visão ultrapassada de que os pais, tanto adultos como adolescentes, não seriam tão relevantes para o desenvolvimento psicossocial da criança, ou pelas crenças ocidentais da importância primordial da maternidade, crenças que não condizem com a importância do pai na vida dos filhos, retratada por inúmeros estudos.

Em particular as vivências do pai adolescente não podem ser desconsideradas ou encobertas pelo fenômeno da gravidez na adolescência, especialmente por este ser frequentemente analisado exclusivamente a partir das vivências maternas. Para Tuffin et al. (2010), os jovens pais em muitos estudos foram analisados indiretamente a partir da perspectiva das mães, fato que gera uma limitação nessas investigações, ao se ignorar importantes diferenças de gênero nas experiências destes jovens pais. Além disto, para Heilborn et al. (2002) há uma grande diversidade presente neste fenômeno encoberto sob o rótulo homogeneizador de "gravidez na adolescência". Existe, por exemplo, uma tendência a pressupor que toda a gravidez ocorrida na adolescência seja não programada e irresponsável, algo que pode ser questionado por alguns estudos. Da mesma forma, Cabral (2003) pontua que os qualificativos "precoce" e "indesejada" nem sempre acompanham o fenômeno da parentalidade na adolescência, o qual tem sido frequentemente tratado de modo padronizado, ignorando-se as diferenças de gênero e de classe social.

O fato é que o fenômeno da parentalidade na adolescência 
constitui-se como um desafio que se situa no impasse entre a possibilidade biológica e a expectativa cultural (Tuffin et al., 2010). Para os autores, este fenômeno envolve não apenas a questão de quando um adolescente tem idade suficiente para tornar-se pai, mas suscita também expectativas sociais quanto à existência de maturidade e responsabilidade para tal. Por estes motivos, eles destacam a grande controvérsia existente em relação a este tema, com algumas culturas definindo a parentalidade na adolescência como um problema de saúde pública, enquanto outras sugerem a indesejabilidade social e moral deste fenômeno. Sem dúvida é um tema a ser tratado em sua diversidade e complexidade, tornando-se importante, para tanto, investigar, dentre outros aspectos, as experiências e expectativas vivenciadas pelos próprios pais adolescentes envolvidos neste processo.

Nesse sentido, faz-se necessário compreender melhor as especificidades concernentes a este processo que pode ser permeado por dificuldades inerentes à sobreposição de dois momentos importantes e críticos na vida de um homem: ser adolescente e ser pai. Sendo assim, o presente estudo teve por objetivo investigar o exercício da função paterna na adolescência, desde a gestação até o primeiro ano de vida do bebê.

\section{Método}

\section{Participantes}

Participaram deste estudo três casais de adolescentes, cuja gestação estava no terceiro trimestre no momento do primeiro contato. Os participantes tinham idades entre 16 e 19 anos e, no momento da gestação, estavam namorando ou morando juntos, e eram de nível socioeconômico baixo. Todos os participantes faziam parte do projeto "Aspectos Biopsicossociais da Gravidez Adolescente: Estudo Longitudinal da Gestação ao Segundo Ano de Vida da Criança - GRADO (Piccinini et al., 2008) que acompanhou cerca de150 gestantes adolescentes e os respectivos pais dos bebês residentes em três regiões metropolitanas do Rio Grande do Sul (Porto Alegre, Santa Maria e Rio Grande), desde o terceiro trimestre de gestação até o segundo ano de vida do bebê. Dentre os critérios de inclusão no estudo estava: não apresentar intercorrências clínicas durante a gravidez, não ter sofrido abuso sexual, e não apresentar transtornos mentais. Para fins do presente estudo foram selecionados três casais que atenderam aos critérios da pesquisa e que participaram das três primeiras etapas de coleta de dados (gestação, três meses após o nascimento e primeiro ano de vida do bebê). A Tabela 1 apresenta algumas das características sociodemográficas dos participantes, tendo por base as informações obtidas na fase inicial da coleta de dados.

\section{Delineamento, procedimento e instrumentos}

Foi utilizado um delineamento de estudo de caso coletivo (Stake, 1994), de caráter longitudinal, a fim de investigar o exercício da função paterna, da gestação ao primeiro ano de vida do bebê. Cada caso foi investigado em três diferentes etapas: terceiro trimestre de gestação, após os três meses do bebê e após um ano de vida do bebê. Para permitir a triangulação dos dados (Stake, 1994) e melhor compreensão dos aspectos analisados, participou do estudo tanto o pai adolescente como a sua companheira.

Tabela 1

Dados Sociodemográficos dos Participantes.

\begin{tabular}{|c|c|c|c|c|c|}
\hline Casais & Idade & $\begin{array}{c}\begin{array}{c}\text { Escolaridade } \\
\text { (anos completos) }\end{array} \\
\end{array}$ & Profissão & Situação Conjugal & Sexo do bebê \\
\hline Casal 1 & & & & Companheiros & Feminino (Bruna) \\
\hline Felipe & 18 & 10 & Web designer & & \\
\hline Margot & 18 & 09 & Estudante & & \\
\hline Casal 2 & & & & Companheiros & Feminino (Luiza) \\
\hline Daniel & 16 & 09 & Estagiário & & \\
\hline Priscila & 16 & 09 & Estudante & & \\
\hline Casal 3 & & & & Companheiros & Feminino (Alice) \\
\hline Matheus & 19 & 05 & Balconista & & \\
\hline Carla & 17 & 09 & Estudante & & \\
\hline
\end{tabular}

Nota. Todos os nomes foram trocados a fim de preservar a identidade dos participantes.

Na primeira etapa, quando o casal adolescente estava no terceiro trimestre de gestação, os pais adolescentes responderam à Ficha de dados sócio-demográficos da família (Nudif, 2008a), à Ficha sobre práticas sexuais e doenças sexualmente transmissíveis (Nudif, 2008b), à Entrevista sobre a gravidez adolescente - Versão pai (Nudif, 2008c), e à Entrevista sobre o relacionamento do casal (Nudif, 2008d). Já na segunda etapa, após o terceiro mês de vida do bebê, os pais responderam à Entrevista sobre a paternidade adolescente e sobre o desenvolvimento do bebê - $3^{\circ}$ mês (Nudif, 2009a) e à Entrevista sobre o relacionamento do casal - $3^{\circ}$ mês (Nudif, 2009b) e, após o bebê completar o primeiro ano de vida, os jovens pais responderam à Entrevista sobre a paternidade adolescente e sobre o desenvolvimento do bebê - $12^{\underline{O}}$ mês (Nudif, 2009c) e à Entrevista sobre o relacionamento do casal - $12^{\circ}$ mês (Nudif, 2009d). Versões adaptadas de todos os instrumentos foram realizadas com as mães.

\section{Resultados e discussão}

Análise de conteúdo qualitativa (Bardin, 1979; Laville \& Dione, 1999) foi realizada a fim de investigar o exercício da função paterna no contexto da adolescência. O exercício da função paterna, analisado aqui com base nas contribuições de diversos 
autores (Le Camus, 2002; Stern,1997; Winnicott,1965/1979), considerou os relatos paternos e maternos em que foi possível identificar menções sobre o apoio oferecido pelo pai à companheira e à relação mãe-filha, sua intermediação nessa relação, quando ele ajudou a mãe a sair do seu estado de fusão com a filha e a retomar seu contato com o mundo externo. Foram também considerados os relatos sobre colocação de limites e ensinamentos fornecidos pelo pai à filha, bem como a possível interferência da mãe sobre o exercício da função paterna, através de incentivos ou, por outro lado, de empecilhos na relação pai-filha.

\section{Casal 1 (Felipe e Margot)}

Os relatos tanto de Felipe quanto de Margot apontaram para o quanto, de maneira geral, ele pareceu funcionar como importante fonte de apoio emocional para ela, desde a gestação, até o último momento em que foram entrevistados, aos doze meses da filha Bruna. Na gestação, embora Felipe demonstrasse certo incômodo com a maior dependência que Margot estava apresentando em relação a ele, entendia tratar-se de um momento particular, em função da gravidez e da eminente chegada da filha:

A forma como as coisas aconteceram tornaram a Margot muito dependente de mim, sabe? Mas é uma coisa que, por enquanto a situação que a gente se encontra, a nossa relação, isso é bem difícil, né. Talvez quando a Bruna já for um pouco maior ela comece a ver, assim, que isso [ser mais independente] vai ser melhor pra ela (Felipe).

Margot, neste período, ressaltou sobre o quanto Felipe lhe estava apoiando, e demonstrando maior sensibilidade para lidar com este período de maior carência. Nesse sentido, ao que parece, Felipe conseguiu oferecer o suporte emocional necessário e importante para que Margot conseguisse adaptar-se melhor e desfrutar mais da gestação.

$\mathrm{O}$ apoio de Felipe à Margot durante o parto também foi um aspecto que chamou a atenção. Felipe, apesar de sentir-se nervoso e preocupado, procurou ficar ao lado de Margot de forma a ajudá-la a sentir-se mais calma. A importância da presença de Felipe neste momento foi confirmada por Margot, que relatou que o apoio dele neste momento foi fundamental, diferente daquele proporcionado pelos profissionais de saúde que ali estavam:

Nossa, se não fosse ele tá do meu lado ia ser muito diferente, ia ser bem difícil, sabe? Porque ele me deu muita segurança, ele ficou do meu lado e segurou a minha mão, me acalmava, sabe, tinha vários enfermeiros, médicos ali do meu lado e tal, não era a mesma coisa, sabe, daí eu acho que se tornou mais fácil este momento pra mim (Margot).

Em relação a este tema Parke (1996) ressaltou que a presença do pai durante o parto pode incrementar ainda mais a experiência emocional vivida pela mãe neste momento. Mais do que isso, ele aponta justamente para a possível diferença que há entre o apoio dos profissionais de saúde e do pai durante o parto. Enquanto, por exemplo, as enfermeiras tenderiam a se ausentar com mais frequência, o pai, além de permanecer ao lado da companheira de forma mais contínua, tenderia a proporcionar maior contato físico, através de toques e carinhos. No caso de Felipe, os relatos parecem confirmar que ele agiu como um acompanhante ativo no processo de parto (Motta \& Crepaldi, 2005) proporcionando à Margot o conforto emocional e a segurança necessários para ajudá-la neste momento.

Felipe também pareceu sensível em perceber que as demandas em relação ao cuidado da filha poderiam estar gerando uma sobrecarga em Margot, especialmente quando Bruna estava com quatro meses, período em que ele relatou estar mais afastado, em função do trabalho e, por esse motivo, inseguro em deixar mãe e filha sozinhas. Sendo assim, Felipe reconhecia e valorizava a importância de que Margot pudesse contar com outras fontes de apoio, especialmente da mãe dela, para ajudá-la a cuidar da filha, ou mesmo para ter tempo para cuidar de si:

Eu vejo que isso é importante um pouco também pra Margot se sentir melhor. É barra pesada assim, tipo, que ela fica um período integral assim com ela, o tempo inteiro mesmo, sabe? Então, sei lá, trinta minutinhos que seja, pra ela já deve ser muito bom, poder, sabe, fazer o que ela quiser (Felipe).

Deste modo, ele parece ter tentado suprir a sua lacuna enquanto parte da matriz de apoio de Margot, incentivando e valorizando a entrada e o auxílio de outras pessoas neste momento, em especial da mãe da companheira, a qual é vista pela literatura como importante fonte de apoio, instrução e de segurança no período pós-parto (Stern, 1997).

Margot, por sua vez, falou sobre o quanto o nascimento de Bruna tinha feito com que ela sentisse uma falta maior do apoio de Felipe e de sua presença ao lado dela e, justamente neste momento em que ela precisava tanto dele, algo que pareceu mudar quando a filha estava com doze meses, período em que Felipe conseguia estar mais presente. Neste período, fora ajudá-la em tarefas concernentes à filha, Margot relatou também sentirse bastante valorizada por Felipe, que costumava elogiá-la não apenas enquanto mãe, mas também como mulher: "Me sinto, me sinto [valorizada]. Ele me trata assim de uma forma que me valoriza bastante, sabe? Ele me admira muito, ele fica me elogiando e tal, como mãe, como mulher". Tais relatos de Margot sinalizam que Felipe possivelmente estaria, através destas falas dirigidas a ela, estabelecendo um importante passo no exercício da função paterna, reconhecendo sua importância não apenas como mãe, mas também enquanto mulher.

No terceiro mês após o nascimento da filha, Felipe também pareceu entender e adequar-se ao momento inicial do relacionamento mãe e filha, caracterizado por uma maior fusão e dependência. A relação do casal havia ficado em segundo plano, e Felipe demonstrou compreender que tal movimento era típico deste novo momento em suas vidas, com a passagem de uma díade para tríade e, mais ainda, deste momento inicial, em que Bruna precisava maciçamente de atenção: "Não tem como, sabe? Porque a Bruna depende muito da Margot ainda. (...) Logo a gente vai poder assim ter um pouco mais de tempo pra nós dois". Por outro lado, justamente por esta característica de maior simbiose no relacionamento entre mãe e filha, ele apresentou certa dificuldade em lidar com o descontentamento de Bruna nos momentos em ela ficava longe da mãe. Já Margot, neste mesmo período em que Felipe falou sobre esta dificuldade, relatou que ele era a única pessoa, além dela, que conseguia estar com a filha 
sem lhe causar estranhamento, demonstrando, assim, reconhecer e valorizar seu papel enquanto cuidador.

Aos doze meses, tanto Felipe, quanto Margot falaram com maior ênfase sobre a falta que estavam sentindo de momentos só para o casal e sobre a dificuldade em manter uma vida sexual satisfatória. Entretanto, eles já pareciam realizar alguns movimentos que sinalizavam uma possível saída deste período de maior simbiose entre mãe e filha. Felipe, que antes buscava intervir o mínimo possível na relação mãe-filha, agora procurava estimular Margot a retomar o seu contato com o mundo externo, incentivando-a a buscar pessoas que lhe eram próximas, e das quais havia se afastado após o nascimento de Bruna: "Até pouco tempo atrás assim, tipo, ela não marcava mais de encontrar nenhuma amiga dela, fazer alguma coisa assim, sabe? Tive meio que insistir pra ela fazer isso assim". Por outro lado, ele se mostrava um pouco descontente por, neste período, Margot tentar limitar sua vida social, queixando-se nos momentos em que saía com os amigos. Ele percebeu também que o trabalho estava sendo uma importante fonte de distração para Margot, de forma a fazê-la sair um pouco daquela rotina em que se dedicava exclusivamente aos cuidados da filha: "O trabalho, digamos assim, é a forma de se distrair dela. O contrário de mim, né, eu me distraio quando tô em casa. Ela se distrai com o trabalho". Margot, por sua vez, permanecia valorizando muito o contato entre pai e filha, a participação de Felipe na vida de Bruna, parecendo, desta forma, exercer também uma das suas funções enquanto mãe, ao facilitar o conhecimento mútuo entre eles e, mais do que isso, ao permitir e valorizar a entrada do pai no mundo da filha (Le Camus, 2002; Winnicott,1965/1979).

Chamou a atenção o modo como Felipe, aos doze meses da filha, falou sobre os momentos em que precisava lhe colocar limites. O que antes era visto por ele como uma dificuldade, agora era percebido como algo agradável, um ensinamento necessário:

No começo era bem difícil porque ela chorava, né, era uma coisa... uma situação que ela não conhecia assim. Aí ela ficava assustada, né? 'Ah, meu pai tá me xingando', aí ela chorava e tal, eu me sentia meio mal assim. Agora acho que é uma coisa muito mais de ensinamento mesmo assim. (...) Me sinto até agradável assim de dizer 'não' pra ela quando ela não deve fazer alguma coisa. Não fico mal (Felipe).

Talvez esta dificuldade inicial fosse justificada pelo fato de pai e filha precisarem de um tempo para o reconhecimento mútuo, para o entendimento das reações e, assim, Felipe sentir maior segurança ao impor limites à Bruna, sem achar que assim estivesse causando algum mal a ela, mas sim, ensinando-a sobre as coisas do mundo, e protegendo-a de eventuais perigos. Ademais, Margot e Felipe pareciam ter formas diferentes de lidar com a filha. Enquanto ela parecia ser mais cuidadosa e protetora, Felipe parecia deixá-la mais livre, demonstrando também entender os momentos em que a filha procurava fazer coisas apenas para chamar a atenção. Tais relatos parecem ir ao encontro do que foi apontado por Le Camus (2002), quando dizia que os pais funcionam como importantes agentes de socialização para os filhos sendo que eles tenderiam a estimulá-los em sua comunicação e em sua aprendizagem, encorajando-os, mais do que as mães, a encontrar soluções por si mesmos.

\section{Casal 2 (Daniel e Priscila)}

Os relatos de Daniel e Priscila revelaram que ele serviu como importante fonte de apoio emocional para ela, em especial nos dois primeiros momentos em que foram entrevistados, durante a gestação e aos três meses de vida de Luiza. Chamou a atenção o relato de Priscila a respeito do quanto Daniel, durante a gestação, estava se mostrando companheiro, algo que superou suas expectativas, pois ela acreditava que ele seria mais desleixado. Já Daniel, quando falou sobre o apoio oferecido à Priscila neste período, destacou mudanças em seus hábitos de vida, ao deixar um pouco de lado as atividades que costumava realizar com frequência antes da gravidez, a fim de poder estar mais com ela.

Por outro lado, cabe ressaltar que aspectos semelhantes também foram mencionados em estudos com pais adultos (Finnbogadottir, Svalenius, \& Persson, 2003) em que alguns pais demonstraram, no início da gestação, sentirem-se culpados por acharem difícil abrir mão da vida antiga, o que gerou sentimentos de confusão e de falta de liberdade. De acordo com os autores, alguns homens expressaram claramente que se sentiam tristes pela perda de sua vida de solteiro, bem como referiram medo de perder sua liberdade e sua vida antiga com os amigos. Sendo assim, tais mudanças referidas por Daniel e confirmadas por Priscila durante o período gestacional parecem ser características da paternidade de um modo geral. O que talvez possa ocorrer é que, durante a adolescência, tais mudanças sejam mais bruscas, em especial para aqueles jovens que levavam uma vida cercada de amigos e colegas não pais (Beers \& Hollo, 2009). Por exemplo, no estudo de Cabral (2003), também com pais adolescentes, eles relataram que a paternidade implicou na necessidade de abrir mão das brincadeiras, zoações e molecagens típicas da vida de adolescente, a fim de passar a outro status que implica mais seriedade, obrigações, vínculos e dependência, e que pressupõe a diminuição do tempo livre e do convívio com os pares.

Daniel pareceu ser uma importante fonte de apoio para Priscila no período seguinte ao nascimento de Luiza quando se demonstrou sensível à maior necessidade de apoio e cuidado à Priscila naquele período. Esta importância pôde também ser constatada a partir do relato emocionado de Priscila sobre o quanto estava gostando da vida que levava com Daniel, e da impossibilidade de imaginar-se sem ele naquele momento:

Eu gosto muito dele assim, sabe? [Emocionada] Agora, no momento que a gente tá, eu não, não me veria sem ele. Bah, se a gente terminasse, sei lá eu o que eu ia fazer, porque é tão bom, sabe? O nosso dia-a-dia assim é tão bom (Priscila).

Já dizia Winnicott (1965/1979) que, para uma mãe, é um alívio verificar que o pai se comporta da maneira como ela esperava. Nesse sentido, Priscila, neste período, demonstrou que parecia estar bastante satisfeita com o apoio recebido de Daniel, que se mostrava bastante prestativo, disponível e presente em sua vida. Sendo assim, ao que parece, Daniel conseguiu, neste período, exercer a função de cuidador (holding) para Priscila (Fulgêncio, 2007), oferecendo o apoio necessário para que ela conseguisse dedicar-se aos cuidados com o bebê, acolhendo-a neste momento peculiar da relação entre mãe e filha. 
Tanto Daniel quanto Priscila destacaram ainda mudança ocorrida sob o ponto de vista de que agora não eram mais apenas um casal, mas sim pai, mãe e filha. Daniel, naquele período, parecia compreender e mesmo gostar do fato de que agora o casal não dispunha mais de períodos para ficarem a sós, estando sempre juntos, só que na companhia da filha: "Sei lá, é que a gente passa o tempo todo juntos, não tem, assim, dizer que a gente precisa de mais tempo porque o dia inteiro a gente passa juntos”. Os relatos de Priscila confirmaram que a relação de casal naquele momento havia se transformado, de modo a incluir a filha. Nesse sentido, todas as atividades do casal, mesmo os momentos de carinho, agora eram divididas com Luiza.

Por outro lado, aos doze meses de vida de Luiza, Priscila demonstrou-se extremamente queixosa por, durante algum tempo, Daniel não ter lhe sido tão apoiador quanto ela esperava que ele fosse. Para ela, a ajuda de Daniel limitava-se a trabalhar e comprar coisas, enquanto o suporte nos cuidados com a filha deixava a desejar. Entretanto, os relatos de Priscila apontaram para rumos contraditórios em relação a este aspecto: ao mesmo tempo em que ela esperava e cobrava de Daniel um maior apoio, em especial no que diz respeito aos cuidados com a filha, parecia sentir-se insegura quanto à capacidade dele em conseguir cuidar de forma adequada:

Mas não, não saio. Deus o livre! Eu não consigo [risos]. Tá certo ele [Daniel] cuidar e tudo, mas eu tô monitorando um pouco, né? Mas sozinho não. Nem pensar! Eu quero ajuda, mas eu quero ficar por perto, assim, né, não sair e deixar ela assim (Priscila).

Embora tal atitude possa refletir a insegurança e a ansiedade experimentadas pelas mães frente aos primeiros momentos de separação com os filhos, fato que pode gerar certa dificuldade por parte delas em deixá-los sem a sua presença (Fulgêncio, 2007; Winnicott, 1963/1983), pode ser vista também como uma dificuldade da mãe de exercer sua função enquanto intermediadora da relação pais-filhos e de facilitadora do conhecimento mútuo entre eles (Winnicott, 1965/1979). Nesse sentido, talvez Priscila estivesse apresentando certa dificuldade em sair deste período de maior fusão com a filha, ao impedir ou criticar as tentativas de Daniel em fazê-la exercer outras atividades além daquelas concernentes à filha, como trabalhar, e também ao tentar controlar ou mesmo impedir um contato maior entre pai e filha quando ela não estava presente.

Soma-se a isso o fato de Priscila relatar certa dificuldade em acolher e retribuir os carinhos de Daniel para com ela neste período. As reações de ciúme da filha à aproximação do casal faziam com que Priscila repelisse Daniel, demonstrando não suportar ou mesmo não saber lidar com tal comportamento da filha:

Ele demonstra bastante carinho por mim, sabe? E até eu não andava demonstrando tanto carinho por ele quanto eu queria, e ele continuava demonstrando. E daí ele até se estressou comigo né, porque cada vez que ele chegava perto de mim, a Luiza já começava a chorar, aí eu 'Ah, não, sai, sai, sai, sai...'. Daí eu já me estressava, sabe? (Priscila).

Nesse sentido, a função do pai enquanto aquele que auxilia a mãe a recuperar-se do estado de preocupação materna primária, ao lembrá-la de que também é uma mulher (Fulgêncio, 2007) parece ter encontrado barreiras importantes no caso de Daniel. Cabe ressaltar que, talvez por coincidência, dentre os três casais entrevistados, Daniel e Priscila foram os únicos que moraram durante todo o período da pesquisa na casa dos pais dela, algo que pode ter representado uma importante fonte de apoio para o casal, mas, por outro lado, gerado uma maior interferência sobre os aspectos de parentalidade destes jovens pai e mãe. Ademais, eles também foram os mais jovens dentre os pais e mães entrevistados e, em especial no caso de Daniel, a chegada da filha parece ter gerado uma repercussão mais conturbada e a necessidade de mudanças mais drásticas em sua vida em relação aos outros pais, o que talvez possa ter sido refletido sobre seu exercício da função paterna.

Ainda em relação à função paterna, de acordo com Winnicott (1965/1979) não está nas mãos da mãe tornar férteis as relações entre pais e filhos, mas está em seu âmbito possibilitá-las, ou, por outro lado, impedi-las ou desfigurá-las. Nesse sentido, para Priscila, parecia que algumas vezes Daniel não sabia se relacionar com Luiza, tratando-a como um "gurizinho", por realizar com ela brincadeiras mais agitadas, algo que fazia Priscila interferir de forma a interromper a brincadeira, ou a fazer Daniel mudar seu jeito de brincar com a filha:

Ah, na verdade, ele cuida ela assim como se tivesse cuidando um gurizinho. Ele tinha que ter tido um gurizinho, né? Porque daí ele quer brincar, quer se atirar no chão. Faz umas brincadeiras de guri. A gente tem que tá toda a hora 'Calma, ela é uma menina. Ela é delicada (Priscila).

Entretanto, é importante ressaltar a impossibilidade de afirmar que tais comportamentos de Priscila indicassem uma tendência a interferir de forma negativa na relação entre Daniel e Luiza, algo que só poderia ser analisado em um período de tempo mais longo. Daniel, por sua vez, falou sobre o quanto seu jeito de lidar com Luiza não era muito bem visto por Priscila. Enquanto ele achava importante estimular uma maior autonomia da filha, deixá-la explorar o ambiente e ajudá-la menos, Priscila, de acordo com ele, costumava interferir mais nas explorações de Luiza, não a deixando levantar-se sozinha quando caía e não soltando sua mão ao caminhar:

É que eu cuido do meu jeito, né? É que eu gosto de deixar ela fazer as coisas, que nem se levantar, sozinha, deixar ela fazer as coisas sozinha pra ela aprender. Já a Priscila não, ela gosta de ajudar (Daniel).

Ele percebia que a sua forma de lidar com Luiza estava auxiliando em seu crescimento, e mostrava-se seguro e confiante no potencial que a filha apresentava no desenvolvimento de novas habilidades. Nesse sentido, apesar de sua pouca idade e do pouco conhecimento a respeito do crescimento e desenvolvimento de crianças pequenas, Daniel parecia exercer de forma adequada a sua função enquanto tutor nas aprendizagens cognitivas da filha, ao propor mais desafios e ao encorajar, mais do que Priscila, Luiza a encontrar soluções por si mesma (Le Camus, 2002).

Em contrapartida, outro aspecto que chamou a atenção em relação ao exercício da função paterna foi a dificuldade de Daniel em impor limites à Luiza nos momentos em que estes se faziam 
apropriados, aspecto que também se fez presente nos relatos de Priscila. Embora considerasse ser a pessoa da família que mais conseguia fazê-lo, Daniel demonstrou dificuldade em lidar com o temperamento da filha, e admitiu que costumava ceder às suas exigências. Soma-se a isso o fato de que Daniel parecia associar a colocação de limites a uma situação de briga e, por este motivo, algo que parecia ser uma fonte de sofrimento para ele: "Eu não gosto de brigar com ela, no caso assim, que nem é pra tirar as coisas dela, assim, que tem que dar uma brigada com ela pra ela entender que não pode". Já para Priscila, esta dificuldade - que também via como dela própria - seria justificada pelo fato de Luiza ser a primeira filha do casal e, por conseguinte, eles não saberem ainda o que teria de ser feito:

A gente ainda não conseguiu dizer 'não' pra ela. Mas a gente vai indo, né? Primeiro filho, né, daí é difícil saber o que tem que fazer e o que não tem que fazer [risos]. Porque ela [filha] pegou o meu ponto fraco, tanto o meu, quanto o do Daniel (Priscila).

Alguns autores ressaltam que uma visão mais negativa dos pais em relação ao temperamento dos filhos, algo que parece mais comumente observado em adolescentes, poderia levar a uma maior dificuldade de interpretação e manejo dos seus comportamentos (Marsiglio \& Cohan, 1997). No caso de Daniel, esta dificuldade de impor limites poderia ter sido ainda agravada pela condição mais delicada de saúde de Luiza, decorrente do quadro de traqueomalácia (uma malformação da traqueia) que, embora já praticamente resolvido, demandava maior cuidado e atenção por parte dos pais. Pode-se cogitar que a condição mais frágil de saúde da filha possa ter suscitado sentimentos de culpa e sofrimento (Castro \& Piccinini, 2002) e, desta forma, influenciado em sua aparente dificuldade em colocar limites. Sendo assim, sem ter a pretensão de determinar os motivos para tal conduta, o fato é que Daniel parecia estar com dificuldades em exercer uma tarefa importante da função paterna neste período. Tal tarefa pressupõe o pai como aquele que, dentre outros aspectos, impõe limites à criança e protege a mãe dos impulsos destrutivos exagerados que a criança possa eventualmente dirigir a ela - onde entraria o comportamento de bater, outrora mencionado por Priscila -, proporcionando as medidas e os contornos necessários a tais comportamentos (Fulgêncio, 2007).

\section{Casal 3 (Matheus e Carla)}

Os relatos tanto de Matheus quanto de Carla revelaram que ele serviu como uma importante fonte de apoio para ela durante a gestação e nos primeiros meses após o nascimento de Alice. Durante a gestação, este apoio foi expresso através dos carinhos e elogios de Matheus para com Carla e de sua maior compreensão e tolerância frente aos momentos de irritação dela e à diminuição do seu desejo sexual naquele período: "Ela não tem vontade [de fazer sexo]. Sei que não é pra sempre, é só por causa dum momento". Nesse sentido, parecia que Matheus estava, adequadamente, servindo como "matriz de apoio" (Stern, 1997) para Carla neste período de maior fragilidade, insegurança e dependência, como é a gestação. No entanto, é importante ressaltar que esta não pareceu constituir-se como uma tarefa fácil para Matheus, em especial no que diz respeito a lidar com o humor irritado de Carla. Tanto que, para ele, o nascimento de Alice parecia representar a possibilidade de que Carla voltasse a ser como era antes da gestação:

Eu demonstro [carinho] pra ela, mas ela só me solta as patas. Só que ela tá se abusando por causa da gravidez, né? Muitas coisas eu não falo, não debato com ela, por causa que ela tá grávida, para fazer as vontades dela. Deixa, ela tá no momento dela, de aproveitar. De repente depois ela muda mesmo (Matheus).

Este aspecto também foi apontado no estudo de Finnbogadottir et al. (2003), realizado com pais suecos adultos entrevistados durante a gestação de suas companheiras, o qual revelou que alguns pais expressaram sentimento de insegurança e ansiedade frente à imprevisibilidade e às mudanças de humor de suas parceiras, além da sensação de que nada daquilo que faziam parecia contentá-las. Pode-se cogitar que tal dificuldade possa ser exacerbada frente ao não planejamento da gravidez e, mais ainda, quando esta ocorre na adolescência, período em que as oscilações de humor já são uma característica bastante comum (Knobel, 1981).

Matheus demonstrou ainda a preocupação em organizar passeios com Carla aos finais de semana, justamente por ela queixar-se para ele sobre estar cansada de ficar apenas em casa. Conforme Heilborn et al. (2002), uma das possíveis repercussões da maternidade sobre a vida das adolescentes de classes populares estaria justamente na retirada delas de um espaço mais público, acirrando a internalidade em relação à casa. De acordo com os autores, são constantes, entre as mães adolescentes de classes populares, as queixas com respeito à solidão e ao isolamento. É importante lembrar que Carla deixou de frequentar a escola durante a gestação e, além disso, o casal parecia ter diminuído drasticamente a sua vida social, deixando de fazer programas que eram habituais no período anterior à gravidez, como ir a shows e festas. Ou seja, é inevitável pensar que as mudanças advindas da gestação e da maternidade parecem exercer uma enorme repercussão sobre o estilo de vida de uma adolescente, especialmente de classe baixa.

Matheus parecia seguir sendo visto como uma importante fonte de apoio para Carla no período seguinte ao nascimento da filha. Para ela, Matheus estava se mostrando bastante prestativo e apoiador, diferente de outros meninos da idade dele que ela conhecia e, mais do que isso, parecia estar correspondendo às expectativas que ela apresentava em relação ao papel paterno: "Eu me sinto feliz de ter encontrado um guri como ele. Porque não é todo guri que assume tudo que ele tá assumindo". Tanto Matheus quanto Carla ressaltaram, na entrevista dos quatro meses, que o casal não dispunha de períodos para estarem a sós, e que as atenções estavam totalmente voltadas para Alice. Neste período, Matheus pareceu lidar adequadamente com o fato de que o nascimento da filha havia gerado uma importante repercussão sobre a vida do casal e, em especial, sobre a vida sexual, e considerava este um aspecto característico da paternidade e, mais ainda, da vida com uma filha pequena, que demandava atenção constante. Por outro lado, para Carla, o nascimento da filha parecia ter gerado um afastamento do casal, que já não trocava carinhos com tanta frequência e que não permanecia mais tanto tempo junto como antes: "Não, eu 
não tenho [demonstrado carinho por Matheus]. Ele se mostrou bastante carinhoso comigo, mas agora tá meio... não tem me mostrado muito. Eu acho que é esse negócio de não ficar mais sozinho, né? Tem sempre ela [filha]".

Chamou a atenção, neste período, que Matheus tenha aparecido, nos relatos de ambos, como aquele que conseguia acalmar a filha nos momentos em que ela chorava sem parar. Enquanto Carla parecia apresentar dificuldade e mesmo sentir-se nervosa frente a este comportamento da filha, Matheus, apesar de sua pouca idade, parecia demonstrar a segurança e a continência para lidar com a situação:

A Carla fica louca que ela [filha] chora, e aí eu só pego... Acho que ela chora pra vir pra mim, eu pego ela e deu. A Carla fica louca! Ela [filha] quer ficar comigo, só eu que acalmo ela (Matheus).

Nesse sentido, ele parecia, nestes momentos em que Carla estava mais sensível e que apresentava dificuldades em conter o choro de Alice, já firmar a sua entrada na vida da filha (Fulgêncio, 2007), oferecendo-se a ela como um elemento diferente e dando o suporte necessário para a contenção de suas tendências instintuais (Passos, 2007). Alice, por sua vez, parecia também já reconhecer a presença do pai e, quem sabe, perceber a diferença entre ele e a mãe, ao acalmar-se justamente nos momentos em que estava em seu colo. Desta forma, ela, à sua maneira, também já parecia converter o pai como uma pessoa importante em sua vida (Winnicott, 1965/1979).

$\mathrm{Na}$ entrevista dos doze meses, o casal estava separado, e em conflito. Neste período, os relatos de Matheus sinalizavam que, mesmo antes da crise conjugal, o casal não dispunha de períodos a sós, e mesmo a vida sexual permanecia restrita. Mais do que isso, os relatos de Carla demonstraram que a relação conflituosa do casal parecia interferir sobre o apoio que ele dispunha para ela, ou melhor, para a falta deste. Sendo assim, neste período, Carla não se sentia apoiada por Matheus, pelo contrário, sentiase agredida e ameaçada por ele. Talvez por este motivo que foram identificados poucos relatos tanto de Matheus quanto de Carla referentes ao exercício da função paterna neste período, em especial relativas aos ensinamentos e à colocação de limites dele para com a filha. Em relação a este aspecto, Matheus apenas comentou brevemente que costumava manejar os episódios de "chilique" da filha através de conversas:

Eu converso com ela [filha], que ela não pode fazer assim, daí ela olha pra mim, ela pára. Eu falo pra ela 'Que feio, tu vai fazer assim com o papai’? Aí quando tu vê ela vem correndo, me abraça e pára de chorar. É tudo questão de conversar, que ela entende (Matheus).

Nesse sentido, a visível instabilidade da relação do casal parecia exercer importante influência sobre o exercício da função paterna de Matheus, em especial no último período em que ele e Carla foram entrevistados, aos doze meses de Alice. Desta forma, a relação conflituosa com Carla parecia ter gerado um afastamento importante de Matheus em relação à filha, e trazendo à tona o risco de um distanciamento permanente, assim como havia acontecido em sua experiência anterior de paternidade. Entretanto, não se pode afirmar que tais dificuldades estejam relacionadas simplesmente ao fato de Matheus e Carla serem adolescentes, por mais que alguns autores ressaltem a maior propensão de conflitos conjugais e do rompimento do casal no contexto da adolescência (Bunting \& McAuley, 2004; Gee $\&$ Rhodes, 2003), fator que, indiretamente, pode constituir-se como uma importante influência sobre os aspectos relativos à paternidade.

\section{Considerações finais}

O presente estudo teve por objetivo investigar o exercício da função paterna no contexto da adolescência. Nesse sentido, os três jovens pais pareceram constituir-se como importantes fontes de apoio para suas companheiras, em especial na gestação e durante os primeiros meses, momentos após o nascimento, algo que foi identificado tanto em seus próprios relatos, quanto no das companheiras. Apesar de sua pouca idade, pareceram compreender e procurar adaptar-se aos períodos de maior fragilidade de suas companheiras, mesmo que por vezes considerassem difícil lidar com a irritabilidade e com a mudança de humor delas durante a gestação, ou com a maior dependência em relação a eles neste período.

Ademais, os pais do presente estudo pareceram, de modo geral, conseguir exercer o papel de tutores nas aprendizagens de suas filhas, estimulando-as em suas aprendizagens e na aquisição de uma maior autonomia Entretanto, algumas dificuldades se fizeram presentes, em especial quanto à colocação de limites. Contudo, não se pode afirmar que tais dificuldades estejam circunscritas ao contexto da adolescência, já que remetem ao exercício da função paterna de um modo geral, o qual é permeado pela própria história de vida do pai e por suas vivências subjetivas enquanto pai, filho e marido. Pode-se pensar, contudo, que esta vivência apresenta algumas particularidades em função de o adolescente comumente estar num período de desenvolvimento que, por si só, já envolva emoções regressivas e reorganização psíquica, assim como acontece durante a transição para a paternidade.

Cabe ressaltar, no entanto, que os participantes deste estudo eram pais de crianças pequenas, de até um ano de idade. Por esse motivo, pode ser interessante desenvolver futuros estudos que investiguem a função paterna no contexto da adolescência ao longo dos diferentes momentos de vida da criança, de suas diferentes etapas maturacionais, para que assim se possa entender melhor as possíveis particularidades desta vivência ao longo de um período maior de tempo. Mais do que isso, para aprofundar a compreensão sobre a relação entre o pai adolescente com seus filhos, seria interessante realizar estudos que investiguem de forma mais direta esta relação, por exemplo, através de observações das interações do dia-a-dia, e como ela se dá ao longo do tempo.

Em suma, os resultados do presente estudo revelaram que a paternidade na adolescência nem sempre pode ser considerada como um acontecimento necessariamente negativo, ou que os jovens pais não possuem condições psicológicas para apresentarem-se implicados na vida de suas companheiras e de seus filhos. Pelo menos isso é o que foi revelado nesse acompanhamento da gestação até o primeiro ano do bebê. 
Obviamente dificuldades mais acentuadas podem aparecer após esse período, quando a criança passa a demandar mais, o que merece ser investigado por novos estudos. Sem querer negar as possíveis dificuldades existentes frente a tal acontecimento, as quais foram discutidas no presente trabalho, torna-se importante analisar o fenômeno da paternidade na adolescência em sua complexidade, para que assim seja possível planejar ações de prevenção e intervenção que visem minimizar os eventuais impactos negativos que possam se dar ao longo do processo de paternidade nesse contexto.

\section{Referências}

Bardin, L. (1979). Análise de conteúdo. São Paulo: Edições 70/Livraria Martins Fontes.

Beers, L. A. S., \& Hollo, R. E. (2009) Approaching the adolescent-headed family: A review of teen parenting. Current Problems in Pediatric and Adolescent Health Care, 39(9), 216-233.

Bunting, L., \& McAuley, C. (2004). Research Review: Teenage pregnancy and parenthood: The role of fathers. Child and Family Social Work, 9, 295-303.

Cabral, C. S. (2003). Contracepção e gravidez na adolescência na perspectiva de jovens pais de uma comunidade favelada do Rio de Janeiro. Cadernos de Saúde Pública, 19(2), 283-292.

Castro, E. K., \& Piccinini, C. A. (2002). Implicações da doença orgânica crônica na infância para as relações familiares: Algumas questões teóricas. Psicologia: Reflexão e Crítica, 15(3), 625-635.

Dias, A. B. D., \& Aquino, E. M. L. (2006). Maternidade e paternidade na adolescência: Algumas constatações em três cidades do Brasil. Cadernos de Saúde Pública, 22(7), 1147-1458.

Finnbogadottir, H., Svalenius, E. C., \& Persson, E. (2003). Expectant first-time fathers'experiences of pregnancy. Midwifery, 19, 96-105.

Fulgêncio, C. D. R. (2007). A presença do pai no processo de amadurecimento: Um estudo sobre D. W. Winnicott (Dissertação de Mestrado). Pontifícia Universidade Católica de São Paulo. São Paulo. Recuperado de http://www. sapientia.pucsp.br//tde_busca/arquivo.php? codArquivo=5106

Gee, C. B., \& Rhodes, J. E. (2003). Adolescent mothers' relationships with their children's biological fathers: Social suport, social strain, and relationship continuity. Journal of Family Psychology, 17(3), 370-383.

Heilborn, M. L., Salem, T., Rohden, F., Brandão, E., Knauth, D., Víctora, ... Bozon, M. (2002). Aproximações socioantropológicas sobre a gravidez na adolescência. Horizontes Antropológicos, 8(17), 13-45. doi: 10.1590/ S0104-71832002000100002

Knobel, M. (1981). A síndrome da adolescência normal. In A. Aberastury \& M. Knobel (Orgs.), Adolescência normal: Um enfoque psicanalítico (pp. 24-62). Porto Alegre: Artes Médicas.

Laville, C., \& Dionne, J. (1999). A construção do saber. Porto Alegre: Artmed.

Le Camus, J. (2002). Le lien père-bébé. Devenir, 14(2), 145-167.

Marsiglio, W., \& Cohan, M. (1997). Young fathers and child development. In M. E. Lamb (Org.), The role of the father in child development (pp. 227-244). Nova Iorque: John Wiley \& Sons.

Motta, C. C. L., \& Crepaldi, M. A. (2005) O pai no parto e apoio emocional: A perspectiva da parturiente. Paidéia, 15(30), 105-118.
Núcleo de Infầncia e Família, NUDIF (2008a). Ficha de dados sócio-demográficos da família. Instituto de Psicologia - UFRGS, Porto Alegre. Instrumento não-publicado.

Núcleo de Infância e Família, NUDIF (2008b). Ficha de práticas sexuais e doenças sexualmente transmissíveis. Instituto de Psicologia-UFRGS, Porto Alegre. Instrumento não-publicado.

Núcleo de Infância e Família, NUDIF (2008c). Entrevista sobre a gravidez adolescente: Versão do pai. Instituto de Psicologia - UFRGS, Porto Alegre. Instrumento não-publicado.

Núcleo de Infância e Família, NUDIF (2008d). Entrevista sobre o relacionamento do casal. Instituto de Psicologia - UFRGS, Porto Alegre. Instrumento nãopublicado.

Núcleo de Infância e Família, NUDIF (2009a). Entrevista sobre a paternidade adolescente e sobre o desenvolvimento do bebê ( $3^{\underline{0}}$ mês). Instituto de Psicologia - UFRGS, Porto Alegre. Instrumento não-publicado.

Núcleo de Infância e Família, NUDIF (2009b). Entrevista sobre o relacionamento do casal ( $3^{\underline{0}}$ mês). Instituto de Psicologia - UFRGS, Porto Alegre. Instrumento não-publicado.

Núcleo de Infância e Família, NUDIF (2009c). Entrevista sobre a paternidade adolescente e sobre o desenvolvimento do bebê ( $12^{\underline{0}}$ mês). Instituto de Psicologia - UFRGS, Porto Alegre. Instrumento não-publicado.

Núcleo de Infância e Família, NUDIF (2009d). Entrevista sobre o relacionamento do casal (12ํㅜ mês). Instituto de Psicologia - UFRGS, Porto Alegre. Instrumento não-publicado.

Parke, R. D. (1996). Fatherhood. Cambridge, Massachusetts: Harvard University Press.

Passos, M. C. (2005). Nem tudo o que muda, muda tudo: Um estudo sobre as funções da família. In T. Féres-Carneiro (Org.), Família e casal: Efeitos da contemporaneidade (pp. 11-23). Rio de Janeiro: Ed. PUC-Rio.

Passos, M. C. (2007). Funções paterna e materna em famílias homoparentais In. T. Féres-Carneiro (Org.), Família e casal: Saúde, trabalho e modos de vinculação (pp. 269-282). Rio de Janeiro: Ed. PUC-Rio.

Piccinini, C. A., Lopes, R. C. S., Marin, A. H., Carvalho, F. T., Henn, C. G., Dias, A. C. G.,... Diehl, A. M. P. (2008). Aspectos biopsicossociais da gravidez adolescente: Estudo longitudinal da gestação ao segundo ano de vida da criança. Projeto de Pesquisa, Instituto de Psicologia, Universidade Federal do Rio Grande do Sul - UFRGS, Porto Alegre.

Schelemberg, J. M., Pereira, L. D. C., Grisard, N., \& Hallal, A. L. C. (2007), Características sócio-econômicas e psicossociais do pai adolescente. Arquivos Catarinenses de Medicina, 36(2), 62-68.

Stake, R. E. (1994). Case Studies. In N. Denzin \& Y. Lincoln (Orgs.), Handbook of Qualitative Research (pp. 236-247). Londres: Sage.

Stern, D. (1997). A constelação da maternidade. Porto Alegre: Artes Médicas.

Tuffin, K., Rouch, G., \& Frewin, K. (2010) Constructing adolescent fatherhood: Responsabilities and intergenerational repair. Culture, Health \& Sexuality, 12(5), 485-498.

Winnicott, D. W. (1979). E o pai? In D. W. Winnicott (Org.), A criança e seu mundo (pp. 127-133). Rio de Janeiro: Zahar Editores. (Obra original publicada em 1965)

Winnicott, D. W. (1983). Da dependência à independência no desenvolvimento do indivíduo. In D. W. Winnicott (Org.), O ambiente e os processos de maturação: Estudos sobre a teoria do desenvolvimento emocional (pp. 79-87). Porto Alegre: Artes Médicas (Obra original publicada em 1963) 
Camila Guedes Henn, doutora em Psicologia pela Universidade Federal do Rio Grande do Sul (UFRGS), é Psicóloga no Grupo Hospitalar Conceição (GHC). Endereço para correspondência: Universidade Federal do Rio Grande do Sul, Instituto de Psicologia: Rua Ramiro Barcelos, 2600/111 - CEP: 90035-003 - Porto Alegre, RS. Telefone: (51) 3308-5058

E-mail: camilahenn@hotmail.com

Cesar Augusto Piccinini, pós-Doutor e Doutor em Psicologia pela University of London, é Professor do Programa de Pós-Graduação em Psicologia da Universidade Federal do Rio Grande do Sul (UFRGS). E-mail: piccinini@portoweb.com.br 